\title{
Tailoring the structural and magnetic properties of Co-Zn nanosized ferrites for hyperthermia applications
}

\author{
C. Gómez-Polo ${ }^{1,2}$, V. Recarte ${ }^{1,2}$, L. Cervera ${ }^{1,2}$, J.J. Beato-López ${ }^{1,2}$, J. López-García ${ }^{1,3}$ \\ J. A. Rodríguez-Velamazán ${ }^{3}$, M.D. Ugarte ${ }^{4.2}$, E. C. Mendonça ${ }^{5}$, J. G. S. Duque ${ }^{5}$
}

${ }^{1}$ Departamento de Ciencias. Universidad Pública de Navarra, Campus de Arrosadia, 31006 Pamplona, Spain.

${ }^{2}$ Institute for Advanced Materials (INAMAT), Universidad Pública de Navarra, Campus de Arrosadia, 31006, Pamplona, Spain.

${ }^{3}$ Institut Laue-Langevin, 71 Avenue des Martyrs, 38000 Grenoble, France

${ }^{4}$ Department of Statistics and O.R., Public University of Navarre, Pamplona, Spain

${ }^{5}$ Programa de Pós-Graduação em Física, Campus Prof. José e Aluísio de Campos, UFS,49100-000 São Cristóvão, SE, Brazil

Abstract - A comparative study of the magnetic properties (magnetic moment, magnetocrystalline anisotropy) and hyperthermia response in Co-Zn spinel nanoparticles is presented. The $\mathrm{Co}_{x} \mathrm{Zn}_{1-x} \mathrm{Fe}_{2} \mathrm{O}_{4}$ nanoparticles $(x=1,0.5,0.4,0.3,0.2$ and 0.1$)$ were synthesized by co-precipitated method and the morphology and mean crystallite size (around $10 \mathrm{~nm}$ ) of the nanoparticles were analysed by TEM Microscopy. Regarding the magnetic characterization (SQUID magnetometry), Co-Zn nanoparticles display at room temperature anhysteretic magnetization curves, characteristic of the superparamagnetic behavior. A decrease in the blocking temperature, $T_{B}$, with the $\mathrm{Zn}$ content is experimentally detected that can be ascribed to the reduction in the mean nanoparticle size as $x$ decreases. Furthermore, the reduction in the magnetocrystalline anisotropy with the $\mathrm{Zn}$ inclusion is confirmed through the analysis of $T_{B}$ versus the mean volume of the nanoparticles and the law of approach to saturation. Maximum magnetization is achieved for $x=0.5$ as a result of the cation distribution between octahedral and tetrahedral spinel 
sites, analysed by neutron diffraction studies. The occurrence of a canted spin arrangement (Yafet-Kittel angle) is introduced to properly fit the magnetic spinel structures. Finally, the heating capacity of these spinel ferrites is analyzed under $a c$ magnetic field (magnetic hyperthermia). Maximum SAR (Specific Absorption Rate) values are achieved for $x=0.5$ that should be correlated to the maximum magnetic moment of this composition.

\section{Corresponding autor.-}

Prof. Cristina Gómez-Polo

Departamento de Ciencias. Edificio de los Acebos.

Universidad Pública de Navarra. Campus de Arrosadia. 31006 Pamplona. Spain

Phone.+34-948169576/Fax: +34-948169565/e.mail: gpolo@ unavarra.es

Keywords.- magnetic nanoparticles; Co-Zn ferrites; cation distribution; magnetic hyperhermia. 


\section{1.- Introduction}

Spinel ferrites $\left(\mathrm{MFe}_{2} \mathrm{O}_{4}\right)$ with different metallic cations $(M: \mathrm{Zn}, \mathrm{Mn}, \mathrm{Co}, \mathrm{Cr}, \mathrm{Ni})$ have been widely analyzed in the literature $[1,2]$. They display interesting magnetic properties not only from a basic point of view (i.e. superparamagnetism, spin glass behavior), but also regarding the wide range of applications in different fields such as magnetic recording, high frequency electronic cores, biomedical applications (hyperthermia, drug delivery, MRI or MPI contrast agents), in the catalytic field or as optical devices [3-6]. In particular, $\mathrm{Zn}$-substituted Co nanoferrites $\left(\mathrm{Co}_{x} \mathrm{Zn}_{1-x} \mathrm{Fe}_{2} \mathrm{O}_{4}\right)$ have received particular focus due to the optimization of their magnetic properties (enhanced magnetization and low magnetocrystalline anisotropy) $[7,8]$.

The characteristic spinel structure of these compounds consists of a cubic compact package of oxianions where tetrahedral and octahedral sites are occupied by the different cations [9]. The cation distribution among octahedral $(B)$ and tetrahedral $(A)$ sites of the face-centered-cubic oxygen lattice determines the magnetic response of the system. Such a cation distribution is usually characterized by the inversion parameter $\gamma$, defined as the fraction of divalent ions on the octahedral sites. $\mathrm{ZnFe}_{2} \mathrm{O}_{4}$ is usually characterized as a normal spinel $(\gamma=0)$ where $\mathrm{Fe}^{3+}$ cations occupy $B$ sites and $\mathrm{Zn}^{2+}$ ions on $A$ sites [10]. Conversely, $\mathrm{Co}^{2+}$ cations tend to occupy $B$ sites in $\mathrm{CoFe}_{2} \mathrm{O}_{4}$ ferrite, leading to a predominantly inverse structure with $\mathrm{Fe}^{3+}$ ions distributed almost equally between $A$ and $B$ sites $(\gamma=1)$ [11]. The antiferromagnetic response in $\mathrm{ZnFe}_{2} \mathrm{O}_{4}$ spinel (Nèel temperature, $T_{N} \approx 10 \mathrm{~K}$ ) is interpreted as a consequence of the antiferromagnetic exchange coupling between the $\mathrm{Fe}^{3+}$ octahedral ions $\left(J_{B B}<0\right)$. However, in $\mathrm{CoFe}_{2} \mathrm{O}_{4}$ the antiferromagnetic superexchange $J_{A B}$ interaction is much stronger than the ferromagnetic exchange $J_{A A}$ and $J_{B B}$. Thus, the magnetic moments of ions on the $B$ lattice $\left(\mathrm{Co}^{2+}\right.$ and $\left.\mathrm{Fe}^{3+}\right)$ are mutually 
antiparallel to the moments on the $A$ lattice. As the octahedral $B$ sites are twice the tetrahedral $A$ sites, a net uncompensated magnetic moment arises leading to a ferrimagnetic behavior with characteristic Curie temperature around $860 \mathrm{~K}$. As Zn replaces Co (decrease of $x$ in $\mathrm{Co}_{x} \mathrm{Zn}_{1-x} \mathrm{Fe}_{2} \mathrm{O}_{4}$ ), $\mathrm{Zn}^{2+}$ ions tend to occupy the tetrahedral $A$ positions, displacing $\mathrm{Fe}^{3+}$ ions from the tetrahedral sites to the octahedral sublattice. However, the particular inversion degree is reported to be dependent on different factors such as synthesis procedure, thermal treatment or grain size [12-14]. In fact, it has been widely reported the occurrence of a maximum value in the saturation magnetization as a function of the $\mathrm{Zn}$ content, where the specific cation distribution between octahedral and tetrahedral sites determine the effective magnetic moment $[7,9,15,16]$. Furthermore, the occurrence of noncollinear spin structures is also invoked as an additional contribution to be taken into account in the analysis of the net magnetic moment in these spinel structures [17]. Nevertheless, irrespectively of the particular cation distribution among the $A$ and $B$ sites, the effective Curie temperature decreases with the $\mathrm{Zn}$ content in the spinel structure as a consequence of the weakening in $A B$ superexchange interaction $[8,18]$.

These two main properties, that is, the increase in the effective magnetic moment accompanied by a decrease in the Curie point, reinforce the magnetic hyperthermia properties of the Co-Zn ferrites. Magnetic hyperthermia, generally ascribed to the medical technology able to lead a temperature increase under the action of an $a c$ magnetic field, has been recently renewed with the employ of magnetic nanoparticles [19]. These biomedical therapies include different approaches as thermo ablation of tumors or drug delivery systems $[20,21]$. In particular, the increase in magnetization together with the control on the Curie point with $x$ in $\mathrm{Co}_{x} \mathrm{Zn}_{1-x} \mathrm{Fe}_{2} \mathrm{O}_{4}$ nanoferrites, represent optimum properties to be applied in hypherthermia applications [22]. While an increase in magnetization has generally associated an increase in the heating efficiency, the control 
of the Curie point around therapeutic temperatures $\left(45^{\circ} \mathrm{C}\right)$ enables the design of selfcontrolled temperature systems. Thus, the inversion degree and cation distribution become the dominant factors determining the heating efficiency of the nanosized systems for magnetic hyperthermia applications. Although Co-Zn ferrites have been widely analyzed in the literature, a comparative study of the particular cation distribution, magnetic properties (i.e. magnetocrystalline anisotropy) and hyperthermia response as a function of the $\mathrm{Zn}$ content has been scarcely analyzed.

Accordingly, in this work the structural, magnetic and magnetic hyperthermia properties of $\mathrm{Co}_{x} \mathrm{Zn}_{1-x} \mathrm{Fe}_{2} \mathrm{O}_{4}$ nanoparticles, synthesized by co-precipitated method, is comparatively analyzed. The Co- $\mathrm{Zn}$ nanoparticles display at room temperature the characteristic superparamagnetic behavior. Maximum magnetization is achieved for $x=$ 0.5 leading to a maximum heating capacity (maximum Specific Absorption Rate, SAR). The evolution of the saturation magnetization with $x$ is analyzed on the basis the spinel cation distribution estimated through neutron diffraction analysis.

\section{2.- Experimental}

$\mathrm{Co}_{x} \mathrm{Zn}_{1-x} \mathrm{Fe}_{2} \mathrm{O}_{4}(x=1,0.5,0.4,0.3,0.2$ and 0.1$)$ nanoparticles were prepared by mixing stoichiometrically $\left.\left(\mathrm{Fe}\left(\mathrm{NO}_{3}\right)_{3} 9 \mathrm{H}_{2} \mathrm{O}\right), \quad \mathrm{Zn}\left(\mathrm{NO}_{2}\right)_{3} 6 \mathrm{H}_{2} \mathrm{O}\right)$ and $\left.\mathrm{Co}\left(\mathrm{NO}_{2}\right)_{3} 6 \mathrm{H}_{2} \mathrm{O}\right)$ synthetized through co-precipitation method following the procedures similar that found in [23]. The final $\mathrm{pH}$ was controlled through solution of $\mathrm{NaOH}(1 \mathrm{M})$, which was added dropwise under constant stirring until the solution reaches $\mathrm{pH}=13$ favoring the precipitation and complete hydrolyzation of the ions. The as-prepared precipitates were collected by centrifugation, washed several times with distilled water, and dried at $50{ }^{\circ} \mathrm{C}$ 
in an oven. After that, the precipitated material was annealed in air at temperatures at 400 ${ }^{\circ} \mathrm{C}$ for 6 hours.

The particle morphology, size distribution, high resolution transmission electron microscopy (HRTEM) and scanning transmission electron microscopy with a high angle annular dark field detector (STEM-HAADF) analysis were performed by using a FEI Tecnai Field Emission Gun operated at $300 \mathrm{kV}$. Magnetic measurements were carried out with a SQUID magnetometer (Quantum Design MPMS XL7). The Curie temperature was estimated through thermogravimetry technique (HI-RES 2950 TA Instruments), analysing sample weight changes as a function of temperature under the action of a magnetic field gradient generated by a permanent magnet (applied magnetic field $\approx 100$ Oe) and an inert atmosphere (Ar) to prevent the oxidation of the nanoparticles. The induction heating curves under an $a c$ field (magnetic hyperthermia) were measured with a home-made set up, composed of a $R C$ resonant circuit connected to a $2 \mathrm{~kW} R F$ power amplifier (Electronic \& Innovation, mod. 1240L). The temperature, $T$, of the nanoparticles (powder) as a function of the induction time, $t$, was measured with a fibre optic thermometer (Neooptics, mod. T1) under an ac magnetic field (frequency $340 \mathrm{kHz}$ ).

Neutron diffraction measurements were performed on the D1B diffractometer, at the Institute Laue-Langevin (Grenoble) at a wavelength of $1.28 \AA$. The cation distribution was determined from diffraction patterns measured at $500 \mathrm{~K}$ in the paramagnetic state. The magnetic order was analyzed from neutron diffraction measurements at $200 \mathrm{~K}$. The atomic and magnetic structures were refined by the Rietveld method using the Fullprof package programs [24]. 


\section{Results and discussions}

\subsection{Structural and magnetic characterization}

Firstly, the morphology and mean crystallite size of the nanoparticles were analyzed by TEM Microscopy. Fig. 1a-c show TEM micrographs for $x=1,0.5$, and 0.1 , respectively, together with the histograms of size distributions, where $d$ represents the diameter of the nanoparticls assuming spherical shape. As can be seen, low particle size dispersion is detected with mean sizes around $10 \mathrm{~nm}$. Regarding the particle size distribution, the log-normal density $\left(f(d)=\frac{1}{d \sqrt{2 \pi} \sigma_{0}} e^{-\left\{\frac{\left(\ln \left(d / d_{0}\right)\right)^{2}}{2 \sigma_{0}^{2}}\right\}} ; \ln \left(d_{0}\right)\right.$ : average of the logarithms of the diameter; $\sigma_{0}$ : standard deviation of $\left.\ln (d)\right)$ represents the best approximation (solid line in the histograms). Such a type of distributions has been previously reported and ascribed to the particular synthesis and grain growth mechanisms in nanoparticle systems [25-27]. Table I summarizes the fitting parameters $d_{0}$ and $\sigma_{0}$, obtained through Origin software (Orthogonal distance regression) as a function of the Co content $(x)$. Furthermore, the mean value $\left\langle d>=\frac{\sum_{i=1}^{n} d_{i}}{n}\right.$ and the standard error of the mean, $\sigma$, are also included. A clear decrease in $d_{0}$ and $\langle d\rangle$ is found with the $\mathrm{Zn}$ content with $x$. Similar results are reported in the literature, indicating the role of $\mathrm{Zn}$ in the control of the nanoparticle growth [28]. Regarding the size polydispersity, two index have been evaluated: $P I_{0}=100 \frac{\sigma_{0}}{d_{0}}$ associated to the lognormal distribution [29] and $P I=100 \frac{\sigma}{<d>}$. As shown in Table I, with the exception of the Co ferrite $(x=1), P I$ ranges below $2 \%$, indicating a nearly monodisperse distribution for the Co- $\mathrm{Zn}$ ferrites [30]. 

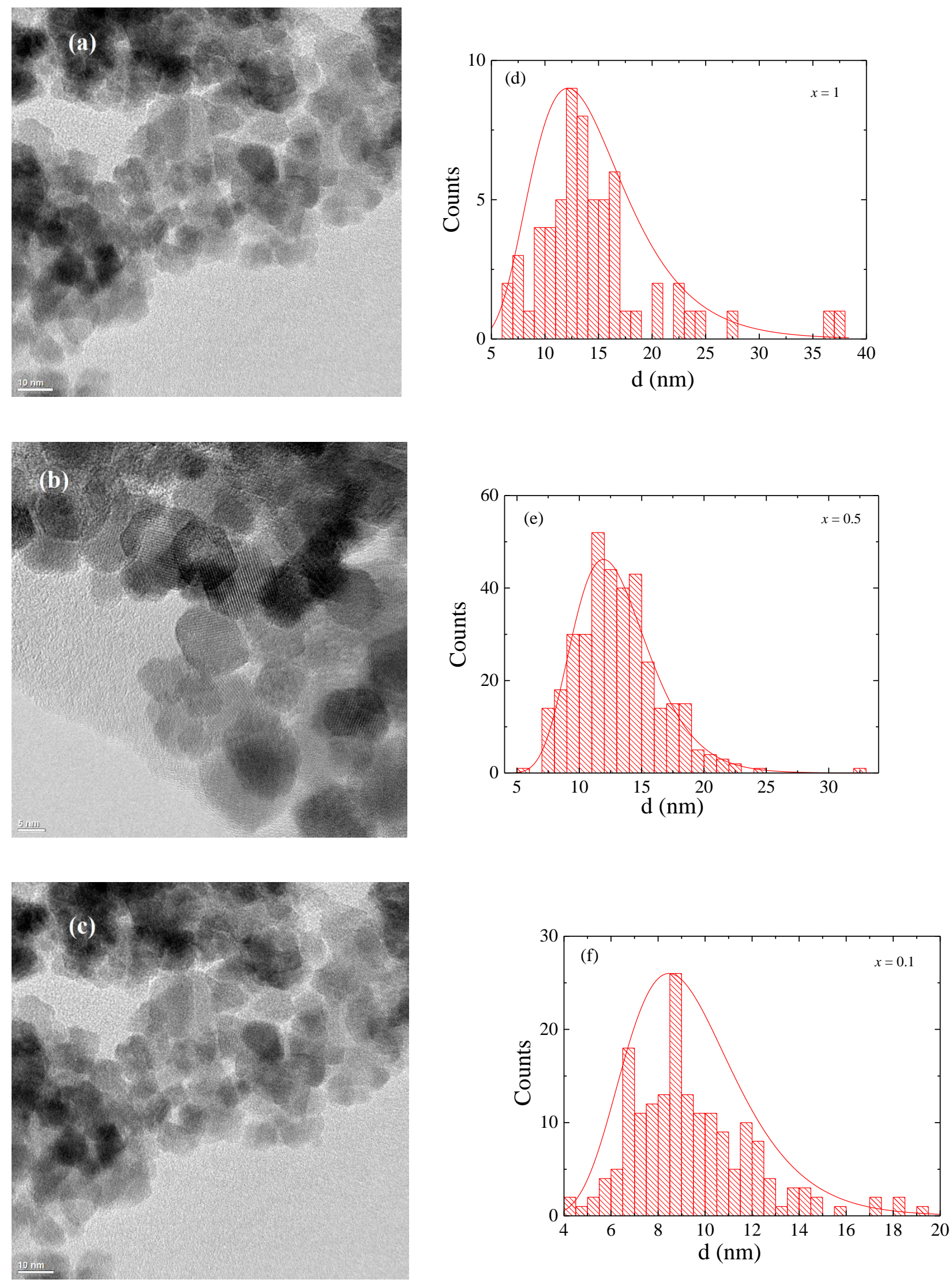

Fig. 1: TEM micrographs for (a) $x=1$, (b) $x=0.5$ and $x=0.1$; (c)-(d) Size distribution of $\mathrm{Co}_{x} \mathrm{Zn}_{1-x} \mathrm{Fe}_{2} \mathrm{O}_{4}$ nanoparticles. Lines are lognormal fits to the data. 
Table I also summarizes the evolution of the mean volume, $V$, of the nanoparticles, assuming spherical shape. Considering the lognormal density, the average volume can be calculated as $V_{0}=\frac{\pi\left(d_{0}\right)^{3}}{6} e^{9 \frac{\sigma_{0}^{2}}{2}}$ [31]. The estimation through the mean value $(<V>=$ $\left.\frac{\pi\langle d\rangle^{3}}{6}\right)$ is also included.

Table I: Nanoparticle size distribution parameters as a function of the Co content $(x)$ : lognormal fitting parameters, $d_{0}, \sigma_{0}$ and polydispersity index $P I_{0}$; mean nanoparticle diameter, $\langle d\rangle$, standard error of the mean, $\sigma$, and polydispersity index, PI; Estimated mean nanoparticle volume considering the lognormal density, $V_{0}$, and through the mean diameter, $\langle V\rangle$.

\begin{tabular}{cccccccc}
\hline $\boldsymbol{x}$ & $\boldsymbol{d}_{\boldsymbol{0}}(\mathrm{nm})$ & $\boldsymbol{\sigma}_{\boldsymbol{0}}$ & $\langle\boldsymbol{d}\rangle \pm \boldsymbol{\sigma}(\mathrm{nm})$ & $\boldsymbol{P I} \boldsymbol{( \mathrm { nm } ^ { - 1 } )}$ & $\boldsymbol{P I}(\boldsymbol{\%})$ & $\boldsymbol{V}_{\boldsymbol{0}}\left(\mathrm{cm}^{3}\right)$ & $\langle\boldsymbol{V}\rangle\left(\mathrm{cm}^{3}\right)$ \\
\hline 1 & $13.0 \pm 0.3$ & $0.19 \pm 0.02$ & $14.7 \pm 0.7$ & 1.46 & 4.8 & $13.4 \times 10^{-19}$ & $16.6 \times 10^{-19}$ \\
0.5 & $12.1 \pm 0.6$ & $0.20 \pm 0.04$ & $13.1 \pm 0.2$ & 1.65 & 1.5 & $11.2 \times 10^{-19}$ & $11.8 \times 10^{-19}$ \\
0.4 & $11.4 \pm 0.2$ & $0.18 \pm 0.04$ & $11.6 \pm 0.2$ & 1.59 & 1.7 & $9.1 \times 10^{-19}$ & $8.2 \times 10^{-19}$ \\
0.3 & $10.6 \pm 0.2$ & $0.26 \pm 0.01$ & $11.1 \pm 0.2$ & 2.45 & 1.8 & $8.4 \times 10^{-19}$ & $7.2 \times 10^{-19}$ \\
0.2 & $9.79 \pm 0.2$ & $0.12 \pm 0.02$ & $10.0 \pm 0.2$ & 1.23 & 2.0 & $5.5 \times 10^{-19}$ & $5.2 \times 10^{-19}$ \\
0.1 & $8.6 \pm 0.2$ & $0.12 \pm 0.02$ & $9.4 \pm 0.2$ & 1.39 & 2.1 & $4.0 \times 10^{-19}$ & $4.3 \times 10^{-19}$ \\
\hline
\end{tabular}

With respect to the magnetic response of the nanoparticles, typical anhysteretic hysteresis loops are obtained for the Co-Zn nanoparticles at room temperature. However, non zero coercivity $(\approx 290 \mathrm{Oe})$ is found in the high magnetocrystalline $\mathrm{CoFe}_{2} \mathrm{O}_{4}$ ferrite. The $Z F C-F C$ magnetization curves (applied magnetic field 50 Oe) confirm the previous magnetic characterization (see fig. 2a). For $x \neq 1$ the samples display the characteristic curves of an assembly of superparamagnetic nanoparticles, that is, a maximum in the $Z F C$ magnetization at $T=T_{B}$ and irreversible $Z F C$ - $F C$ curves for $T<T_{B}$. The maximum in the ZFC magnetization curve can be strictly associated to the blocking temperature $T_{B}$ for non-interacting particles with narrow barrier distribution (monodisperse nanoparticles). However, the evaluation of $T_{B}$ from the maximum in the $Z F C, T_{\max }$, should be properly 
corrected depending on the particular size distribution $\left(T_{\max }=\beta<T_{B}>; \beta>1\right)$ [32]. Other factors, such as nanoparticle interactions modify the position of the maximum and effective blocking temperature [33]. Anyway, a clear increase of the blocking temperature with $x$ can be concluded that should be mainly ascribed to the increase in the mean volume of the superparamagnetic particles. Considering the relationship between the thermal energy, $k_{B} T_{B}\left(k_{B}\right.$ : Boltzmann constant) and the magnetocrystalline energy barrier, $K V(K$ : magnetocrystalline uniaxial anisotropy constant), for $d c$ measurements in superparamagnetic nanoparticles, $K$ can be estimated through the following relationship:

$$
25 k_{B} T_{B}=K V
$$

Fig. $2 \mathrm{~b}$ shows the estimated $T_{B}$ from the maximum in the $Z F C$ curves of the Co$\mathrm{Zn}$ ferrites $(x \neq 1)$ versus the mean volume nanoparticle employing the two volume estimations displayed in table I $\left(V_{0}\right.$ and $\left.\langle V\rangle\right)$. In both cases, a linear relationship is obtained indicating the dominant role of the nanoparticle volume on the evolution of $T_{B}$ with $x$, showing a slope nearly independent on the volume estimation procedure. The estimated value $\left(K \approx 0.9 \times 10^{6} \mathrm{erg} / \mathrm{cm}^{3}\right)$ is slightly lower than the reported value for bulk $\mathrm{CoFe}_{2} \mathrm{O}_{4}\left(1.8-3.0 \times 10^{6} \mathrm{erg} / \mathrm{cm}^{3}\right)$ [34]. Notice that the correction of the blocking temperature taking into account the particular size distribution would give rise to a further decrease in the estimated $K$ value and would confirm the decrease in the anisotropy constant upon $\mathrm{Zn}$ inclusion. 

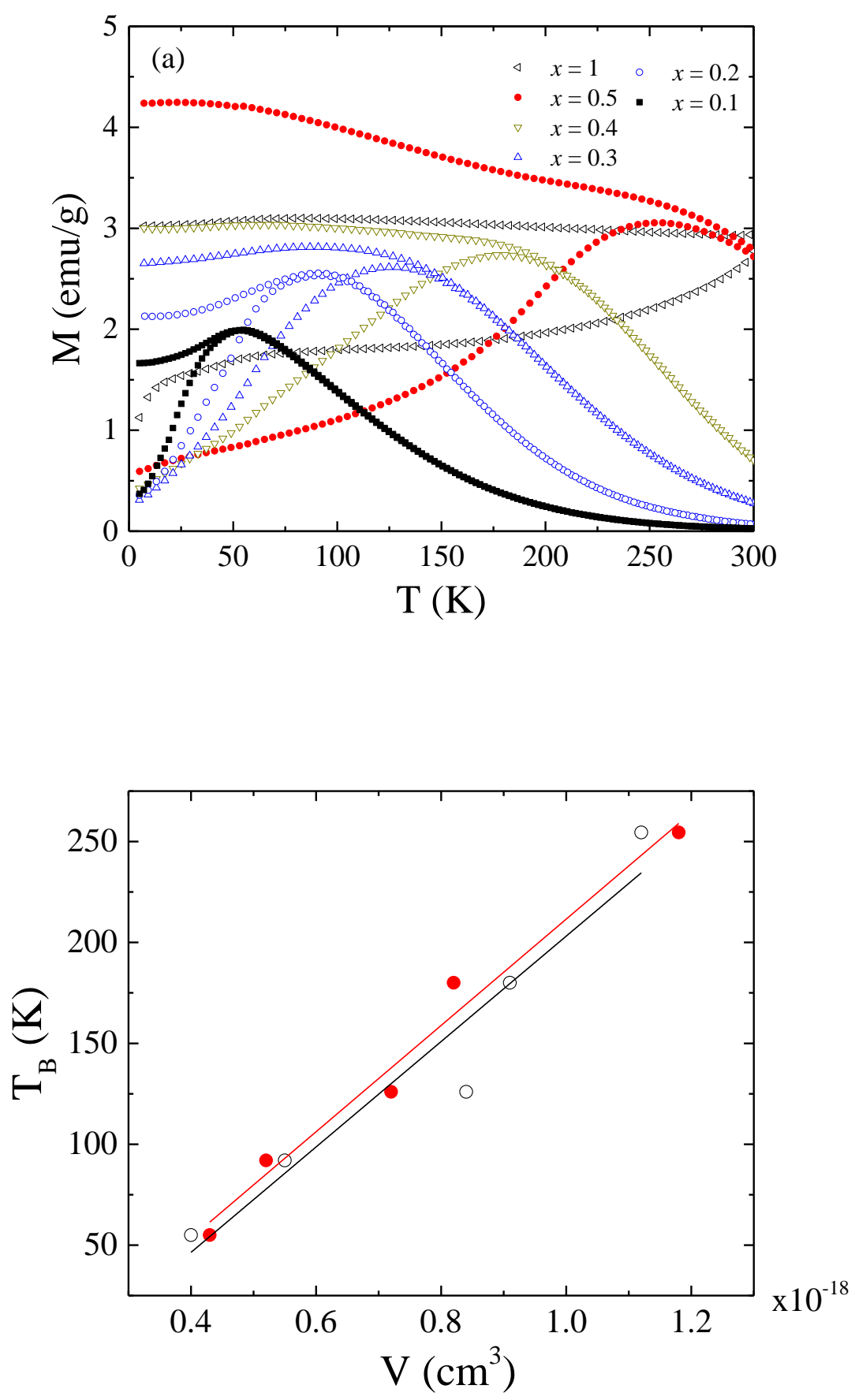

Fig. 2: (a) ZFC-FC magnetization curves (applied field $50 \mathrm{Oe}$ ) for the $\mathrm{Co}_{x} \mathrm{Zn}_{1-x} \mathrm{Fe}_{2} \mathrm{O}_{4}$ nanoparticles; (b) Blocking temperature, $T_{B}$, versus the mean volume $V$ of the nanoparticles: (o) $V_{0}$ and $(\bullet)\langle V\rangle$.

Regarding the high field magnetization, fig. 3 shows its temperature dependence 
under an applied magnetic field $\mu_{0} H=6 \mathrm{~T}$ for the set of analysed nanoparticles. As previously reported, the inclusion of $\mathrm{Zn}$ in the spinel structure promotes an increase in the high field magnetization (increase of the effective magnetic moment) for $x=0.5$ in comparison with the Co based ferrite $(x=1)$.

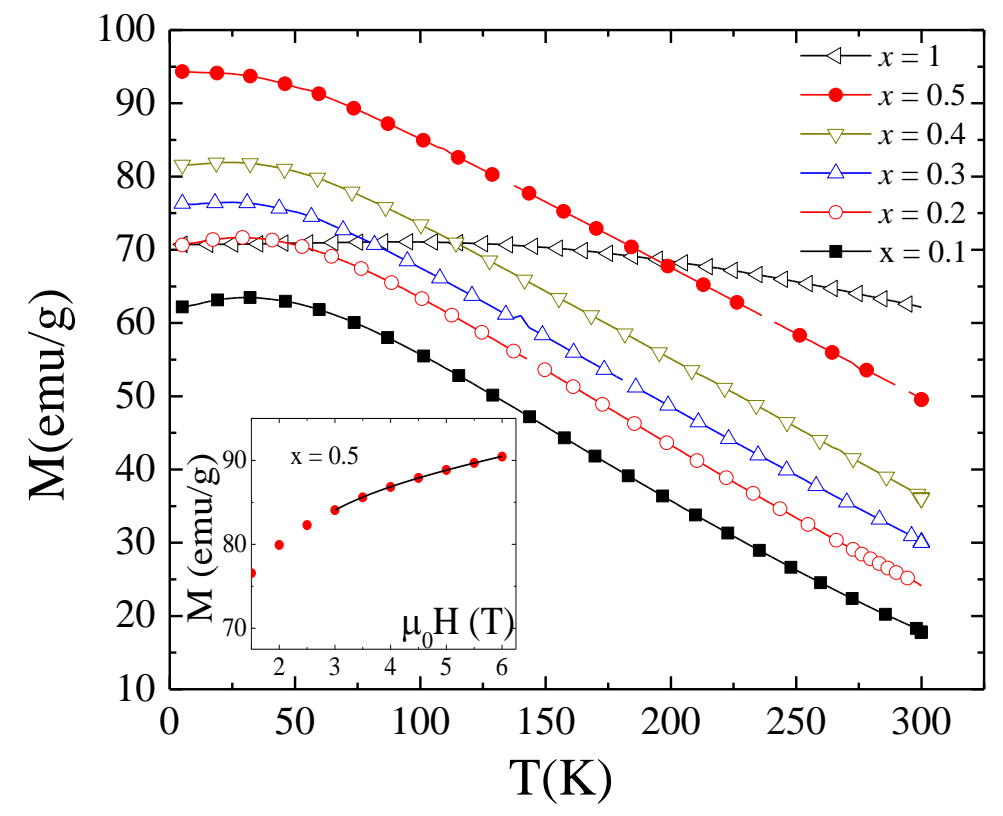

Fig. 3: High field magnetization curves (applied field $\mu_{0} H=6 \mathrm{~T}$ ) for $\mathrm{Co}_{x} \mathrm{Zn}_{1-x} \mathrm{Fe}_{2} \mathrm{O}_{4}$ nanoparticles. Inset: Approach to saturation for $x=0.5$ at $T=5 \mathrm{~K}$ (solid line: fitting according eq. 2).

However, it should be pointed out that the samples are not saturated at maximum applied field, even though for $T<T_{B}$. In fact, a slight maximum in the magnetization curve is detected around $30-40 \mathrm{~K}$ for the Co-Zn nanoparticles $(x \neq 1)$, clearly visible for the highest $\mathrm{Zn}$ content samples. Such a behaviour could indicate a certain degree of magnetic frustration at low temperatures and the departure (even under high applied magnetic field) of the characteristic spin wave (Bloch) law. This magnetic anomaly is confirmed through the inspection of the $F C$ curves (see fig. 2a). Instead of the characteristic increase in the $F C$ curves as $T$ decreases below the blocking peak of non- 
interacting nanoparticles, a decrease or a slight dip is detected. This behaviour is characteristic of a magnetic frustration of spin-glass state and has been previously reported in the literature in $\mathrm{Zn}$ based Co ferrites [35].

In order to further analyse the low temperature magnetic state, the approach to saturation law was applied to fit the reversible magnetization response $(M-H)$ curves in the range from 3 to $6 \mathrm{~T}$ for $T=5 \mathrm{~K}$ (see as an example the inset in fig.3) [36]:

$$
M(T)=M_{S}(T)\left(1-\frac{a}{H}-\frac{b}{H^{2}}\right)+\chi_{h f} H
$$

where $M_{S}$ is the saturation magnetization and $\chi_{h f}$ the high field susceptibility resulting from the slight linear increase in magnetization by the application of $H$. The term $b / H^{2}$ is correlated to the effect of the magnetocrystalline anisotropy, $K$, that for the case of independent grains with cubic symmetry is given by $b=\frac{8 K^{2}}{105 M_{S}^{2}}$ [37]. The second term $a / H$ is associated to the contribution of local inhomogeneities (i.e. structural defects, nonmagnetic inclusions or microstresses) and is usually disregarded in the analysis of nanosized systems. In fact, this parameter should be fixed equal to 0 to properly fit the experimental curves for the set of analysed nanoparticles. Table II summarizes the obtained fitting parameters, together with the estimated values of the anisotropy magnetocrystalline constant from $b$ parameter at $5 \mathrm{~K}$.

Table II: Magnetic parameters obtained from the approach saturation law at $5 \mathrm{~K}$.

\begin{tabular}{ccccc}
\hline $\boldsymbol{x}$ & $\boldsymbol{M}_{\boldsymbol{S}}(\mathrm{emu} / \mathrm{g})$ & $\boldsymbol{b}\left(\mathrm{Oe}^{2}\right)$ & $\boldsymbol{K}\left(\mathrm{erg} / \mathrm{cm}^{3}\right)$ & $\chi_{\boldsymbol{h f}}\left(\mathrm{Oe}^{-1}\right)$ \\
\hline 1 & 75.7 & $1.2 \times 10^{8}$ & $15.3 \times 10^{6}$ & 0 \\
0.5 & 83.7 & $3.7 \times 10^{8}$ & $9.3 \times 10^{6}$ & $1.3 \times 10^{-4}$ \\
0.4 & 68.4 & $4.3 \times 10^{8}$ & $8.1 \times 10^{6}$ & $1.9 \times 10^{-4}$ \\
0.3 & 62.2 & $4.4 \times 10^{8}$ & $7.5 \times 10^{6}$ & $2.1 \times 10^{-4}$ \\
0.2 & 57.1 & $5.0 \times 10^{8}$ & $7.3 \times 10^{6}$ & $2.6 \times 10^{-4}$ \\
0.1 & 43.2 & $5.2 \times 10^{8}$ & $5.6 \times 10^{6}$ & $2.7 \times 10^{-4}$ \\
\hline
\end{tabular}


Firstly, the increase in $M_{S}$ with the $\mathrm{Zn}$ substitution in the Co ferrite is confirmed for $x=$ 0.5. A further increase in the $\mathrm{Zn}$ content $(x<0.5)$ promotes a diminution in the effective magnetic moment of the spinel structure. It should be noted the decrease of $\chi_{h f}$ with $x$, displaying a null value for Co ferrite $(x=1)$. In fact, the reinforcement of the high field susceptibility with the $\mathrm{Zn}$ content has associated the occurrence of the magnetic anomaly at low temperatures (namely, maximum in the high field magnetization and decrease in the $F C$ curve below $T_{B}$ ). The occurrence of a canted spin arrangement (see the following section) and its reinforcement with the $\mathrm{Zn}$ content could play a dominant role in the observed phenomena. Anyway, $A C$ magnetic susceptibility characterization is now in progress to analyze in detail the magnetic anomaly and to check the possible spin-glass nature in these Co-Zn nanosized systems.

With regard to the anisotropy estimation, the decrease in $K$ with the $\mathrm{Zn}$ substitution can be clearly outlined [38]. However, the estimated $K$ values are close to one order of magnitude higher than those obtained from $T_{B}$ (eq. 1). Nevertheless, it should be pointed out the marked temperature dependence of the anisotropy constant in this type of ferrites [39, 40]. In fact, the magnetocrystalline anisotropy constant is reported to markedly increase at low temperatures, displaying a strong size dependence (i.e. increase in $K$ as $\langle d\rangle$ decreases) [41]. Such an increase has been systematically reported in ferromagnetic nanoparticles and usually ascribed to the surface anisotropy contribution inherent of these nanometer systems [42].

On the other side, as previously outlined, the $\mathrm{Zn}$ substitution promotes a net diminution in the Curie temperature in these Co- $\mathrm{Zn}$ ferrites as a consequence of the weakening of the $A-O-B$ interaction. Fig. 4 shows the thermogravimetric curves for the Co-Zn ferrites samples, where $F_{m}(\%)$ is calculated as the relative changes in the sample 
weight, $W$, under the action of the magnetic field gradient, taken the weight at $573 \mathrm{~K}$, $W(573)$, the normalized factor $\left(F_{m}(\%)=\frac{(W(T)-W(573))}{W(573)} \times 100\right)$. A clear decrease in the Curie temperature can be deduced as the $\mathrm{Zn}$ content increases (i.e. $T_{C}(x=0.5) \approx 440 \mathrm{~K}$; $\left.T_{C}(x=0.5) \approx 360 \mathrm{~K}\right)$. Similar values are reported in the literature [18].

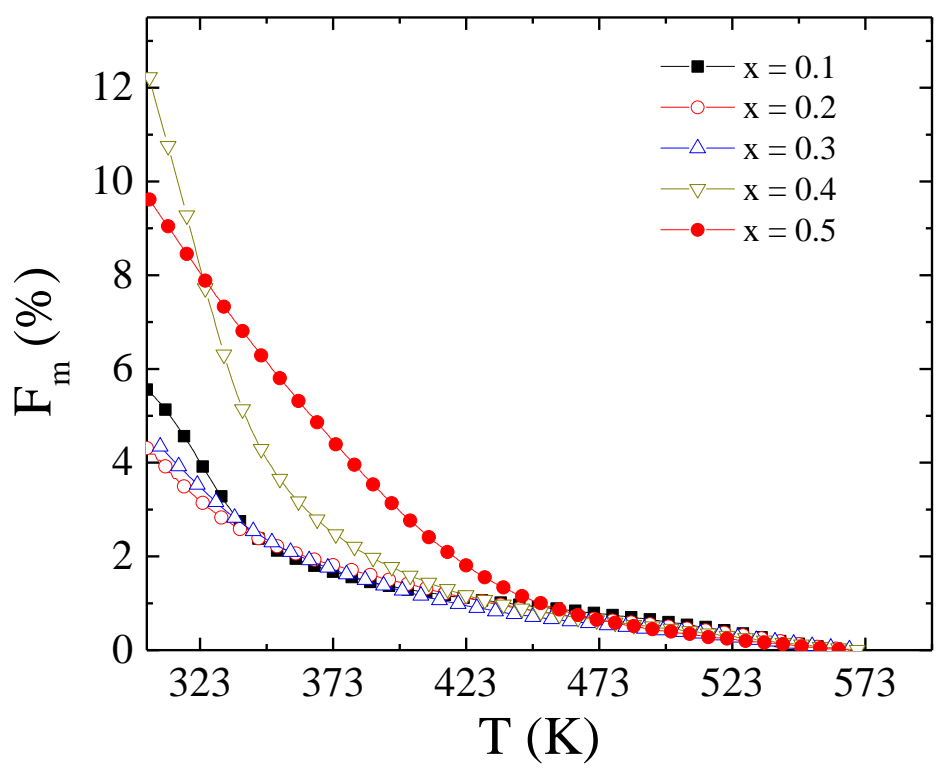

Fig. 4: Thermogravimetric curves for the ferrite $\mathrm{Co}_{x} \mathrm{Zn}_{1-x} \mathrm{Fe}_{2} \mathrm{O}_{4}$ nanoparticles.

\subsection{Neutron diffraction analysis}

Neutron diffraction measurements were carried out for $\mathrm{Co}_{x} \mathrm{Zn}_{1-x} \mathrm{Fe}_{2} \mathrm{O}_{4}(x=0.5$, $0.4,0.3,0.2$ and 0.1$)$ samples at $500 \mathrm{~K}$ and $200 \mathrm{~K}$. High temperature measurements, above magnetic ordering temperatures, allow determining the cation distribution. Once the atomic occupation is fixed, the measurements at low temperature allow analyzing the magnetic order. As an example, fig. 5 shows the measured (dots) and calculated neutron 
diffraction patterns (line), as well as the standard differences between the measured and calculated profiles for the samples with $x=0.1$ and $x=0.3$ at $500 \mathrm{~K}$ and $200 \mathrm{~K}$.
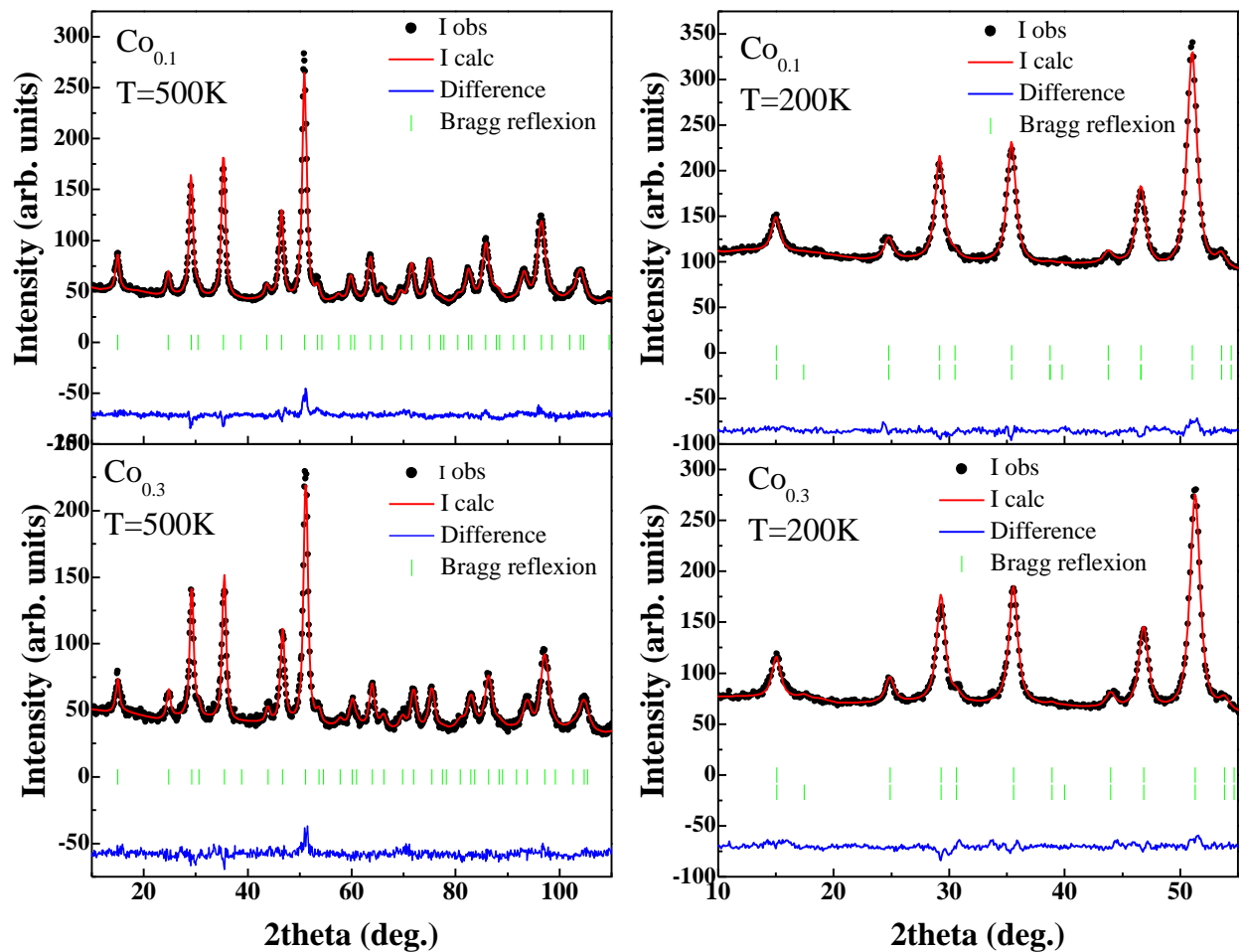

Fig. 5: Experimentally measured neutron diffraction pattern (dots), the fitting of the full measured spectrum (red line) and the standard differences between the measured and calculated profiles (blue line) for the samples $x=0.1$ and $x=0.3$ at $500 \mathrm{~K}$ and $200 \mathrm{~K}$.

The crystallographic structure and the cation distribution were determined from neutron diffraction measurements carried out at $500 \mathrm{~K}$. The structural parameters obtained by Rietveld refinements are shown in Table III. 
Table III: Parameters obtained from Rietveld refinement of the $F d \overline{3} m$ structure.

\begin{tabular}{|c|c|c|}
\hline Sample & Position & Atom Occupancy (\%) \\
\hline $\begin{array}{l}\mathrm{Co}_{0.5} \mathrm{Zn}_{0.5} \mathrm{Fe}_{2} \mathrm{O}_{4} \\
\mathrm{a}=\mathrm{b}=\mathrm{c}=8.3799(4) \AA \\
\mathrm{Grain} \text { Size }=71.99(7) \AA \\
\mathrm{R}=6.31\end{array}$ & $\begin{array}{l}\text { Tetrahedral } A(x=y=z=0.125) \\
\text { Octahedral } B(x=y=z=0.5) \\
\text { Oxygen }(x=y=z=0.2588)\end{array}$ & $\begin{array}{c}\text { Co-29(2)//Zn-37(1)/ Fe-34(1) } \\
\text { Co-10(3)/ Zn-06(2)/ Fe-84(1) } \\
\text { O-100 }\end{array}$ \\
\hline $\begin{array}{l}\mathrm{Co}_{0.4} \mathrm{Zn}_{0.6} \mathrm{Fe}_{2} \mathrm{O}_{4} \\
\mathrm{a}=\mathrm{b}=\mathrm{c}=8.3917(4) \AA \\
\mathrm{Grain} \operatorname{Size}=61.78(5) \AA \\
\mathrm{R}=6.76\end{array}$ & $\begin{array}{l}\text { Tetrahedral } A(x=y=z=0.125) \\
\text { Octahedral } B(x=y=z=0.5) \\
\text { Oxygen }(x=y=z=0.2588)\end{array}$ & $\begin{array}{c}\text { Co-15(2)//Zn-51(1)/ Fe-34(1) } \\
\text { Co-13(2)//Zn-05(1)/ Fe-82(1) } \\
\text { O-100 }\end{array}$ \\
\hline $\begin{array}{l}\mathrm{Co}_{0.3} \mathrm{Zn}_{0.7} \mathrm{Fe}_{2} \mathrm{O}_{4} \\
\mathrm{a}=\mathrm{b}=\mathrm{c}=8.3988(5) \AA \\
\text { Grain Size }=63.56(6) \AA \\
\mathrm{R}=6.11\end{array}$ & $\begin{array}{l}\text { Tetrahedral } A(x=y=z=0.125) \\
\text { Octahedral } B(x=y=z=0.5) \\
\text { Oxygen }(x=y=z=0.2587)\end{array}$ & $\begin{array}{c}\text { Co-11(2)//Zn-61(1)/ Fe-28(1) } \\
\text { Co-08(2)//Zn-09(1)/ Fe-83(1) } \\
\text { O-100 }\end{array}$ \\
\hline $\begin{array}{l}\mathrm{Co}_{0.2} \mathrm{Zn}_{0.8} \mathrm{Fe}_{2} \mathrm{O}_{4} \\
\mathrm{a}=\mathrm{b}=\mathrm{c}=8.4213(3) \AA \\
\mathrm{Grain} \text { Size }=64.75(4) \AA \\
\mathrm{R}=4.67\end{array}$ & $\begin{array}{l}\text { Tetrahedral } A(x=y=z=0.125) \\
\text { Octahedral } B(x=y=z=0.5) \\
\text { Oxygen }(x=y=z=0.2584)\end{array}$ & $\begin{array}{c}\text { Co-10(2)//Zn-63(1)/ Fe-27(1) } \\
\text { Co-04(2)//Zn-11(1)/ Fe-85(1) } \\
\text { O-100 }\end{array}$ \\
\hline $\begin{array}{l}\mathrm{Co}_{0.1} \mathrm{Zn}_{0.9} \mathrm{Fe}_{2} \mathrm{O}_{4} \\
\mathrm{a}=\mathrm{b}=\mathrm{c}=8.4314(3) \AA \\
\mathrm{Grain} \mathrm{Size}=61.24(3) \AA \\
\mathrm{R}=5.83\end{array}$ & $\begin{array}{l}\text { Tetrahedral } A(x=y=z=0.125) \\
\text { Octahedral } B(x=y=z=0.5) \\
\text { Oxygen }(x=y=z=0.2584)\end{array}$ & $\begin{array}{c}\text { Co-03(2)//Zn-68(1)/ Fe-29(1) } \\
\text { Co-03(3)//Zn-11(2)/ Fe-86(1) } \\
\text { O-100 }\end{array}$ \\
\hline
\end{tabular}

Experimental patterns can be very well fitted assuming a single cubic spinel structure, $(F d \overline{3} m)$ space group. In the refinement procedure the scale factor, $2 \theta$ zero position, background, peak profile function, cell parameter and the oxygen position, with $x=y=z$ (Wyckoff position 32e), were taken as adjustable parameters. The cation positions were fixed by assuming two available crystallographic sites, tetrahedral $A$ site $(x=y=z=0.125$, Wyckoff position $8 \mathrm{a})$ and octahedral $B$ site $(x=y=z=0.5$, Wyckoff position 16d). Concerning the atomic distribution, only the cation occupancy in both sublattices (tetrahedral and octahedral) were refined, by assuming the distribution of Co, Fe and $\mathrm{Zn}$ on the two available crystallographic sites within the constraints of full site occupancy.

The cell parameter linearly decreases with increasing Co concentration (see fig. 6) in agreement with the substitution of $\mathrm{Zn}^{2+}(0.74 \AA$ ionic radius $)$ by the smaller $\mathrm{Co}^{2+}$ ions (0.65 $\AA$ ionic radius) ions [12, 43-45]. This linear behavior is also in agreement with 
the Vegard rule [46] and confirms that Co is going into the spinel structure. The $a$ values lie within the range of lattice constants $0.837 \AA$ (for $\mathrm{CoFe}_{2} \mathrm{O}_{4}$ ) and $0.84 \AA$ (for $\mathrm{ZnFe}_{2} \mathrm{O}_{4}$ ) [47]. The lattice parameter of mixed $\mathrm{Co}_{x} \mathrm{Zn}_{1-x} \mathrm{Fe}_{2} \mathrm{O}_{4}$ ferrites often shows a linear behavior between both extreme values in the complete range of compositions $(x=0$ - 1) [43-45, 48]. In any case, discrepancies and deviations from the Vegard rule may appear due to the presence of vacancies and differences in the cation distribution due to the different methods of nanoparticle synthesis [49]. The contrast of neutron scattering lengths of Co $(2.49 \mathrm{fm}), \mathrm{Fe}(9.45 \mathrm{fm})$, and $\mathrm{Zn}(5.68 \mathrm{fm})$ allows determining the cation distribution in both the tetrahedral and octahedral sites, see Table IV. Compositions determined from Rietveld refinement are in agreement with stoichiometric ones showing a slight deviation except for samples with $\mathrm{x}=0.3$ and 0.4 which show an excess of $\mathrm{Zn}$. $\mathrm{CoFe}_{2} \mathrm{O}_{4}$ ferrites revealed an inverse spinel structure, in which Co ions preferentially occupy the $B$ sites and $\mathrm{Fe}$ ions are distributed between both, $A$ and $B$ sites. Conversely, in $\mathrm{ZnFe}_{2} \mathrm{O}_{4}$ ferrites the $\mathrm{Zn}$ ions have a strong preference to occupy the $A$ sites showing a normal spinel structure. For the $\mathrm{Co}_{x} \mathrm{Zn}_{1-x} \mathrm{Fe}_{2} \mathrm{O}_{4}$ ferrites the Rietveld refinements determine that $\mathrm{Co}, \mathrm{Fe}$ and $\mathrm{Zn}$ atoms occupy both sites showing a mixed ferrite character, table IV. The inversion parameter $\gamma$, defined as the fraction of divalent ions on the octahedral sites, shows a slightly increase with Co content from $\gamma=0.28$ to $\gamma=0.32$. Concerning the occupancy of A sites by divalent metal ions, $\mathrm{M}^{2+}, 80 \%$ of the $\mathrm{M}^{2+}$ are $\mathrm{Zn}$ ions in the case of the $\mathrm{Co}_{0.1} \mathrm{Zn}_{0.9} \mathrm{Fe}_{2} \mathrm{O}_{4}$ ferrite. The mixed character evolves with increasing Co content in such a way that $62 \%$ of the $\mathrm{M}^{2+}$ ions in tetrahedral positions are Co ions for the $\mathrm{Co}_{0.5} \mathrm{Zn}_{0.5} \mathrm{Fe}_{2} \mathrm{O}_{4}$ ferrite. 
Table IV. Cation distribution determined from neutron diffraction; $n_{B}^{N}\left(\mu_{B}\right)$, theoretical

\begin{tabular}{ccccccc}
\hline \multicolumn{1}{c}{ Sample } & Cationic distribution & $\boldsymbol{n}_{\boldsymbol{B}}^{\boldsymbol{N}}\left(\boldsymbol{\mu}_{\boldsymbol{B}}\right)$ & $\boldsymbol{n}_{\boldsymbol{B}}^{\boldsymbol{H}}\left(\boldsymbol{\mu}_{\boldsymbol{B}}\right)$ & $\boldsymbol{\Theta}_{\boldsymbol{Y} \boldsymbol{K}}\left(^{\circ}\right)$ & $\boldsymbol{m}\left(\boldsymbol{\mu}_{\boldsymbol{B}}\right)=\boldsymbol{m}_{\boldsymbol{B}}\left(\boldsymbol{\mu}_{\boldsymbol{B}}\right)-\boldsymbol{m}_{\boldsymbol{A}}\left(\boldsymbol{\mu}_{\boldsymbol{B}}\right)$ \\
\hline $\mathbf{C o}_{0.5} \mathbf{Z n}_{\mathbf{0} .5} \mathbf{F e}_{2} \mathbf{O}_{\mathbf{4}}$ & $\left(\mathrm{Co}_{0.22} \mathrm{Zn}_{0.37} \mathrm{Fe}_{0.34}\right)_{\mathrm{A}}\left[\mathrm{Co}_{0.20} \mathrm{Zn}_{0.12} \mathrm{Fe}_{1.68}\right]_{\mathrm{B}} \mathrm{O}_{4}$ & 6.5 & 3.61 & 47.8 & $1.98=3.58(26)-1.60(18)$ \\
$\mathbf{C o}_{0.4} \mathbf{Z n}_{\mathbf{0 . 6}} \mathbf{F e}_{2} \mathbf{O}_{\mathbf{4}}$ & $\left(\mathrm{Co}_{0.15} \mathrm{Zn}_{0.51} \mathrm{Fe}_{0.34}\right)_{\mathrm{A}}\left[\mathrm{Co}_{0.26} \mathrm{Zn}_{0.10} \mathrm{Fe}_{1.64}\right]_{\mathrm{B}} \mathrm{O}_{4}$ & 6.7 & 2.97 & 55.3 & $1.45=2.96(38)-1.51(25)$ \\
$\mathbf{C o}_{0.3} \mathbf{Z n}_{\mathbf{0} .7} \mathbf{F e}_{2} \mathbf{O}_{4}$ & $\left(\mathrm{Co}_{0.11} \mathrm{Zn}_{0.61} \mathrm{Fe}_{0.28}\right)_{\mathrm{A}}\left[\mathrm{Co}_{0.16} \mathrm{Zn}_{0.18} \mathrm{Fe}_{1.66}\right]_{\mathrm{B}} \mathrm{O}_{4}$ & 7.0 & 2.70 & 59.9 & $1.31=2.60(32)-1.29(22)$ \\
$\mathbf{C o}_{0.2} \mathbf{Z n}_{\mathbf{0 . 8}} \mathbf{F e}_{2} \mathbf{O}_{\mathbf{4}}$ & $\left(\mathrm{Co}_{0.10} \mathrm{Zn}_{0.63} \mathrm{Fe}_{0.27}\right)_{\mathrm{A}}\left[\mathrm{Co}_{0.08} \mathrm{Zn}_{0.22} \mathrm{Fe}_{1.70}\right]_{\mathrm{B}} \mathrm{O}_{4}$ & 7.1 & 2.48 & 62.2 & $1.15=2.10(34)-0.95(24)$ \\
$\mathbf{C o}_{\mathbf{0 . 1}} \mathbf{Z n}_{\mathbf{0 . 9}} \mathbf{F e}_{2} \mathbf{O}_{\mathbf{4}}$ & $\left(\mathrm{Co}_{0.03} \mathrm{Zn}_{0.68} \mathrm{Fe}_{0.29}\right)_{\mathrm{A}}\left[\mathrm{Co}_{0.06} \mathrm{Zn}_{0.22} \mathrm{Fe}_{1.72}\right]_{\mathrm{B}} \mathrm{O}_{4}$ & 7.2 & 1.87 & 67.2 & $0.81=1.81(26)-1.00(18)$
\end{tabular}

magnetic moment per f.u.; $n_{B}^{H}\left(\mu_{B}\right)$, experimental magnetic moments per f.u. determined from magnetic measurements; $\Theta_{Y K}$, Yafet and Kittel angle; $m\left(\mu_{B}\right)$, collinear components of the magnetic moments per $f . u$. determined from neutron diffraction.

In order to study the magnetic ordering with respect to $\mathrm{Zn}$ concentration, the magnetic moment values were estimated by considering the cation distribution and magnetic moments of individual ions. The magnetization depends on the cation distribution among $A$ and $B$ sites. According to Néel's two-sublattice model of ferrimagnetism, the magnetic moments of ions on the tetrahedral $(A)$ and octahedral $(B)$ sites couple antiferromagnetically in a collinear structure, leading to a net magnetic moment per formula unit at $0 \mathrm{~K}$ that is simply the numerical difference between sublattice magnetizations [50]. Thus, the magnetic moment per formula unit is $n_{B}^{N}\left(\mu_{B}\right)=M_{B}-M_{A}$, where $M_{B}$ and $M_{A}$ are the $B$ and $A$ sublattice magnetic moment, respectively. $n_{B}^{N}\left(\mu_{B}\right)$ values were calculated using the cation distribution determined from neutron diffraction and the ionic magnetic moments of $\mathrm{Fe}^{3+}$ and $\mathrm{Zn}^{2+}$ as $5 \mu_{B}$ and $0 \mu_{B}$, respectively. $\mathrm{Co}^{2+}$ exhibits an important orbital contribution to the magnetic moment $[51,52]$. In this way, the experimental value, due to the spin-orbit coupling, differs from the S-pure value of $3 \mu_{B}$, being usually smaller $[51,52]$. Then, we have considered a value of 2.1 
$\mu_{B}$ for $\mathrm{Co}^{2+}$ in our calculations. It can be seen that $n_{B}^{N}\left(\mu_{B}\right)$ increases with $\mathrm{Zn}$ content (table IV). To compare with experimental results, the magnetic moments per formula unit, $n_{B}^{H}\left(\mu_{B}\right)$, shown in Table IV, were calculated from the following formula: $n_{B}^{H}\left(\mu_{B}\right)=$ \{molecular weight/5585\} $x M_{S}$ where, $M_{s}$ is the saturation magnetization obtained from magnetic measurements at $5 \mathrm{~K}$ taken from table II. On the contrary that in the case of the theoretical magnetic moment, the experimental one diminishes with the content in $\mathrm{Zn}$. This discrepancy can be explained on the basis of the three-sublattice model proposed by Yafet and Kittel ( $\mathrm{Y}-\mathrm{K}$ model) [53]. According to this model there is a canted spin arrangement where the $B$ lattice can be divided into two sublattices each having magnetic moments equal in magnitude and oppositely canted at the same angle, $\Theta_{Y K}$, relative to the moment of the $A$ lattice. The $\Theta_{Y K}$ angle can be estimated from $n_{B}^{H}\left(\mu_{B}\right)=M_{B} \cos \theta_{Y K}-$ $M_{A}$ where $n_{B}^{H}\left(\mu_{B}\right)$ is the experimental magnetic moment and $M_{B}$ and $M_{A}$ are the $\mathrm{B}$ and $\mathrm{A}$ sublattice magnetic moment, respectively. The observed decrease of the $\Theta_{Y K}$ angle with increasing Co content (see fig. 7) is in agreement with previous results [44], and suggests a strengthening of the $B-B$ interaction, decreasing the $A-B$ interactions.

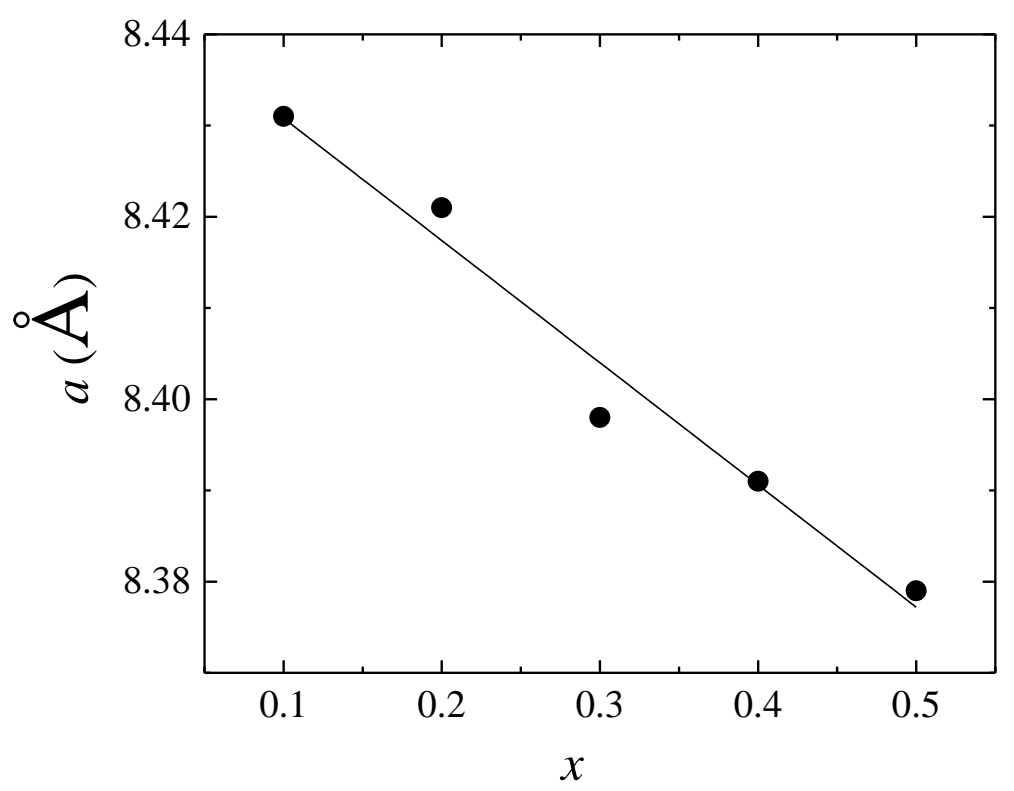

Fig. 6: Variation of the cell parameter, $a$, with Co content, $x$ 
Neutron diffraction measurements at $200 \mathrm{~K}$ were carried out in order to obtain experimental insight into the spin arrangement. Rietveld refinements were performed considering a simple model with a collinear ordering of magnetic moments for the $A$ and $B$ sites [39]. Owing to the limited number of magnetic refection, we refined two average magnetic moments, one for cations at tetrahedral positions and the other one for cations at octahedral positions. The cell parameter and oxygen position were also taken as adjustable parameters, fixing the cation distribution obtained in paramagnetic state. Table IV summarizes the results of the magnetic refinement, being $m\left(\mu_{B}\right)=m_{B}\left(\mu_{B}\right)-m_{A}\left(\mu_{B}\right)$ the net moment in the collinear arrangement. The net magnetic moment $m\left(\mu_{B}\right)$ shows the same dependence on Co content than the moments determined by magnetometry measurements but lower values. Although the magnetic moments are less than the theoretical moments (and those obtained by other techniques), the moments of the respective sites give reasonable values. The values obtained by neutron diffraction are usually lower because they have been measured without applied magnetic field and at higher temperature and because they only reflect the long-range ordered moment, not accounting for the disordered moment (mainly at the shell of the particles $[29,54,55]$ ) that gets instead polarized in in-field techniques [39]. A rough estimation of the $Y-K$ angle can also be made from the magnetic moment at the $B$ sites $m_{B}$ obtained by neutron diffraction and the magnetic moment $M_{B}$ calculated using the cation distribution and the ionic magnetic moments. Since $\cos \left(\Theta_{Y K}^{N}\right)=m_{B Z} / M_{B}$, it can be obtained a similar trend with the $\mathrm{Zn}$ content than the values estimated from the magnetic measurements. 


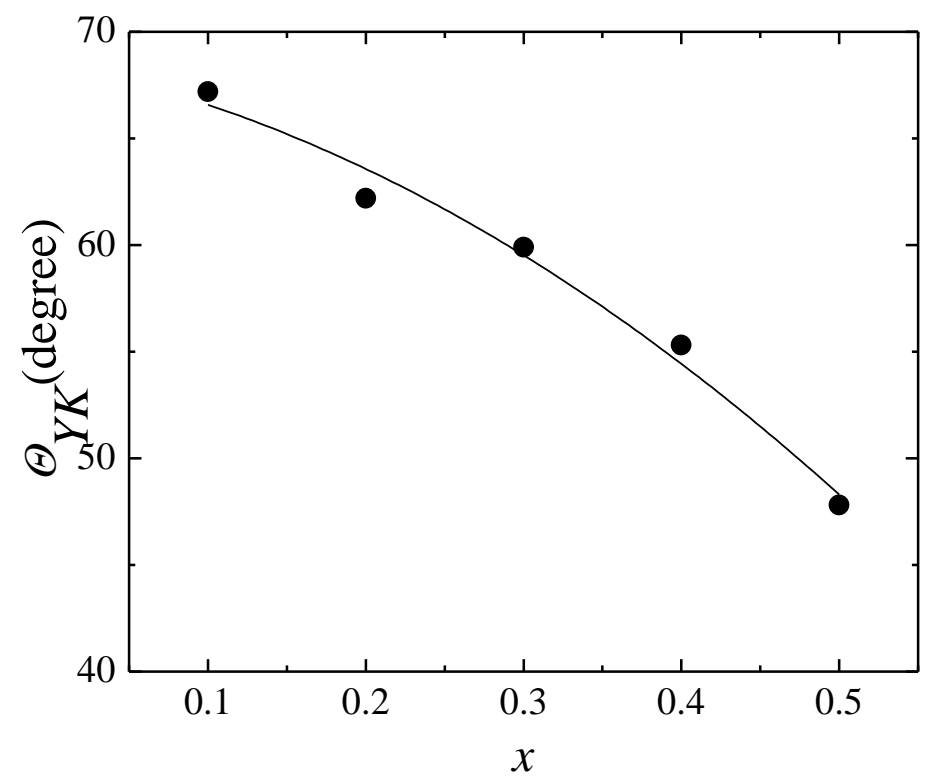

Fig. 7: Variation of the $Y-K$ angle with Co content obtained from magnetic measurement at $5 \mathrm{~K}$.

\subsection{Magnetic hyperthermia}

Fig. 8 displays the temperature, $T$, versus time $t$, for the set of magnetic nanoparticles under an $a c$ applied magnetic field of amplitude $H_{a c}=288$ Oe. Due to the non adiabatic experimental conditions, a nearly constant maximum temperature is achieved as a consequence of the energy heat balance between the heat generated by the magnetic nanoparticles and heat losses. Higher maximum temperatures, $T_{\max }$, are achieved for those samples with higher magnetization, in particular for the Co-Zn ferrite with $x=0.5$ (see fig. 9a) where $\Delta T_{\max }=T_{\max }-T_{0}\left(T_{0}\right.$ : initial sample temperature) is plotted as a function of $x$ for different sample masses, $m_{M N P}$. 


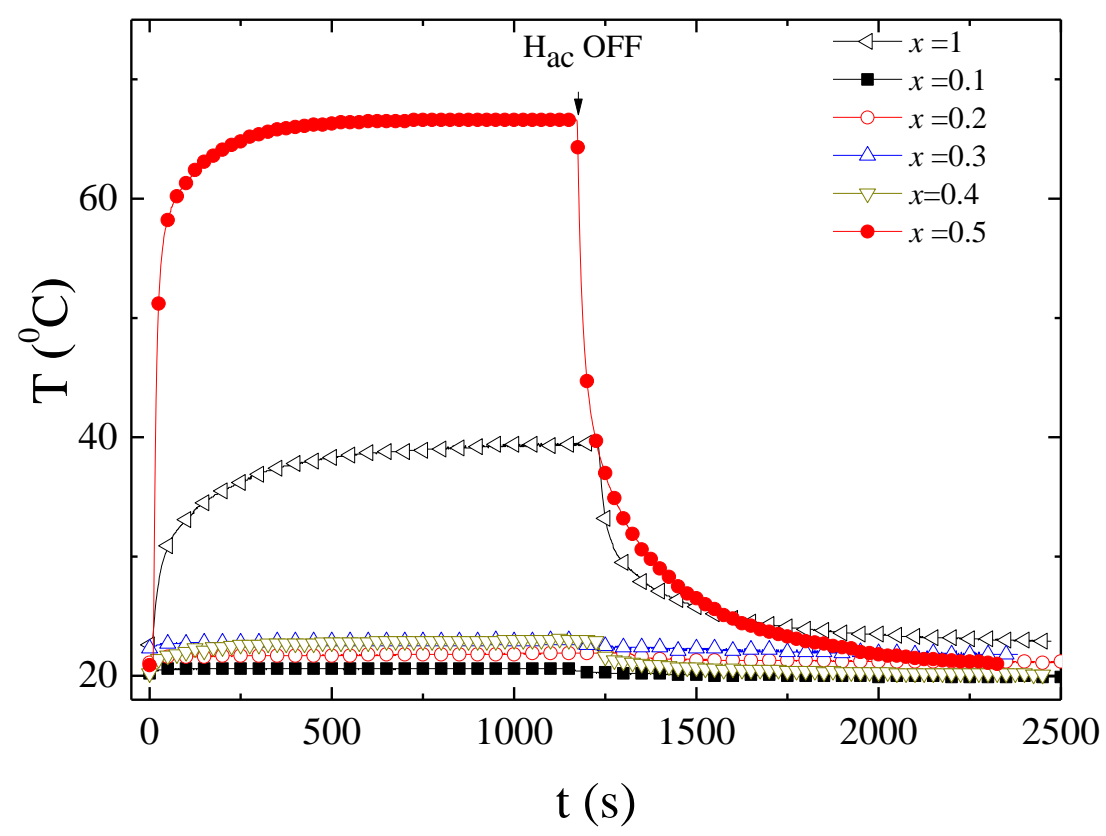

Fig. 8: Temperature, $T$, versus induction time, $t$, for the $\mathrm{Co}_{x} \mathrm{Zn}_{1-x} \mathrm{Fe}_{2} \mathrm{O}_{4}$ nanoparticles $\left(m_{M N P}=28 \mathrm{mg}\right)$.

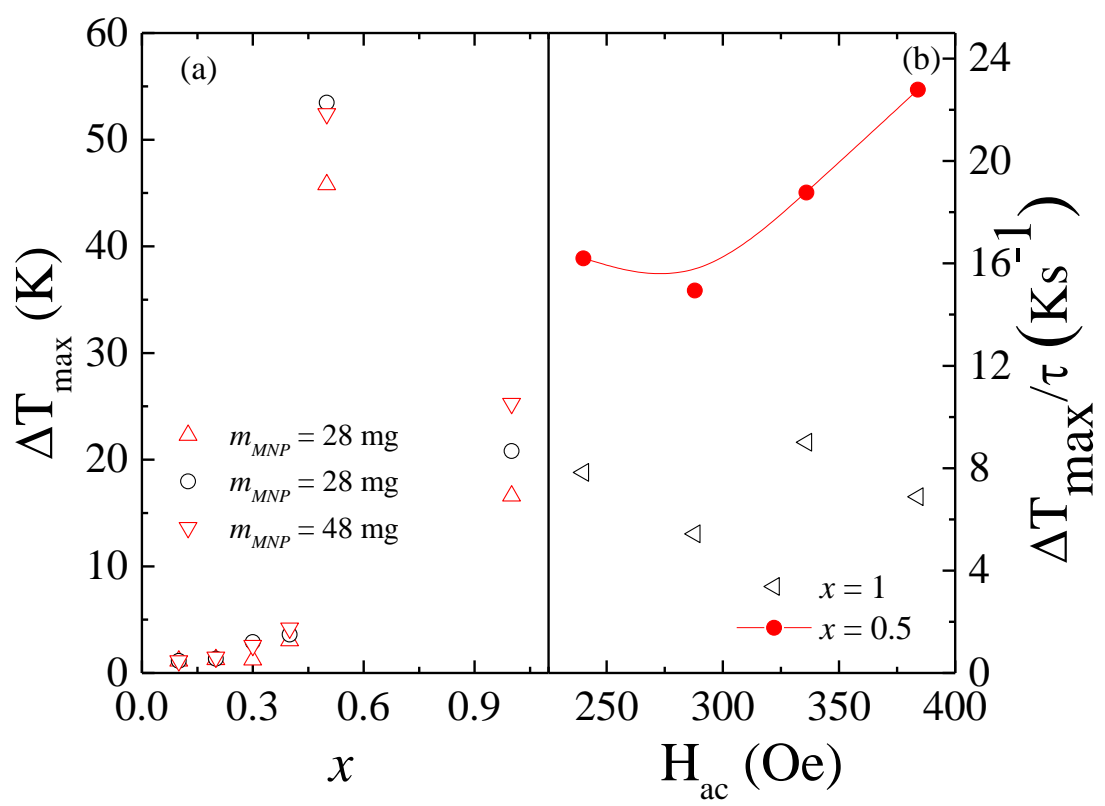

Fig. 9: (a) Maximum temperature, $\Delta T_{\max }$, versus Co content $x$, for the $\mathrm{Co}_{x} \mathrm{Zn}_{1-x} \mathrm{Fe}_{2} \mathrm{O}_{4}$ nanoparticles for different nanoparticle mass, $m_{M N P}$; (b) slope $\left(\frac{\Delta T_{m}}{\tau}\right)$ as function of the applied $H_{a c}$ field for $x=1$ and $x=0.5\left(m_{M N P}=28 \mathrm{mg}\right)$. 
The sharp temperature decreases for $t \approx 1125 \mathrm{~s}$ takes place as a consequence of the switch off of $H_{a c}$ and the quick heat dissipation due to the non adiabatic conditions and the thermal interaction with the environment. Under this isoperibol conditions, where the temperature of the sample varies but the temperature of its environment remains constant, the specific absorption rate, $S A R$, can be estimated through initial slope method [56]:

$$
S A R=\left.\frac{C}{m_{M N P}} \frac{d T(t)}{d t}\right|_{t \rightarrow 0}
$$

where $C$ is the heat capacity of the system (measured in $\mathrm{J} \mathrm{K}^{-1}$ ). The experimental exponential increase (heating) or decrease (cooling) in $T$ can be analyzed taking into account a linear temperature dependence of the heat power losses $\left(P_{L}(T)=L\left[T(t)-T_{0}\right]\right.$, $L$ a constant). Accordingly, the following expressions are usually employed to describe $T(t)$ under non adiabatic conditions: $T(t)=T_{0}+\Delta T_{\max }\left(1-e^{-t / \tau}\right)$ and $T(t)=T_{0}+$ $\Delta T_{\max }\left(e^{-t / \tau}\right)$ for heating and cooling, respectively, where $\tau$ represents time constant given by $\tau=C / L$. Thus, $S A R$ can be calculated under these non-adiabatic isoperibol conditions as:

$$
S A R=\frac{C}{m_{M N P}} \frac{\Delta T_{m}}{\tau}
$$

Since the samples are in powder form, $C=\mathrm{c} m_{M N P}\left(c\right.$ : specific heat measured in $\left.\mathrm{Jg}^{-1} \mathrm{~K}^{-1}\right)$ and the estimated $S A R$ according this initial slope method should not depend on $m_{M N P \text {. }}$ Fig. 9b shows the estimated slope $\left(\frac{\Delta T_{m}}{\tau}\right)$ as function of the applied $H_{a c}$ field for those samples displaying higher heating efficiency ( $x=1$ and $x=0.5$ ). Again, maximum $S A R$ values should be expected for $x=0.5$. In this case, a clear enhancement is observed in the heating capacity of the sample as $H_{a c}$ increases as widely reported in different nanosized systems [57, 58]. Considering $c \approx 0.6 \mathrm{Jg}^{-1} \mathrm{~K}^{-1}$ as reported in similar spinel ferrites [59], maximum $S A R$ around $10 \mathrm{~W} / \mathrm{g}$ are obtained for $x=0.5$, similar to those reported for Co- 
Zn [22] and other nanoferrites systems [58]. Nevertheless, the self-regulation properties of these nanoparticle systems is not clearly demonstrated due to the non-adiabatic experimental conditions. The maximum heating temperature is always below the effective Curie point as a consequence of large heat loss contributions. Furthermore, in a typical hyperthermia experiment, the heat transmission from the magnetic nanoparticles to the solution where they are immersed, modifies the actual mean temperature and accordingly the SAR estimation. These effects should be taken into account in the analysis of the self-regulation properties of these nanosized systems. New measurements are now in progress, reducing heat dissipation, in order to verify the self-regulated properties of these Co-Zn nanoparticles, that is, control of $T_{\max }$ by the paramagnetic state of the ferrite $\left(T_{\max } \approx T_{C}\right)$.

\section{Conclusions}

A comparative analysis of the structural, magnetic and magnetic hyperthermia properties of $\mathrm{Co}_{x} \mathrm{Zn}_{1-x} \mathrm{Fe}_{2} \mathrm{O}_{4}(x=1,0.5,0.4,0.3,0.2,01)$ nanoferrites, prepared by coprecipitation method, is presented. The structure evolution, characterized through TEM microscopy and neutron diffraction, shows a decrease in the mean grain size of the nanoparticles and the cell parameter with $\mathrm{Zn}$ content in the samples. Regarding the magnetic response, Co-Zn nanoparticles display at room temperature the characteristic anhysteretic magnetic response of superparamagnetic nanoparticles. The blocking temperatures, characterized through the $Z F C-F C$ magnetization curves, decrease with the $\mathrm{Zn}$ content as a result of the decrease in the mean nanoparticle volume. The $\mathrm{Zn}$ inclusion in the spinel structure promotes a reduction in the magnetocrystalline anisotropy in comparison with the highly anisotropic $\mathrm{CoFe}_{2} \mathrm{O}_{4}$ ferrite. The neutron diffraction analysis clearly confirms the dominant role of cation distribution between the octahedral and 
tetrahedral sites in the evolution of the effective magnetic moment and the achievement of a maximum in the saturation magnetization for $x=0.5$. However, the occurrence of canted spin arrangement is introduced to properly describe the magnetic spinel structures, increasing the characteristic Yafet-Kittel angle with the Zn content. Finally, optimum heating capacities are obtained for those samples with highest magnetization $(x=0.5)$. The control of the Curie point with the $\mathrm{Zn}$ content around therapeutic temperatures enable the design of self-controlled temperature hyperthermia agents based on these Co-Zn nanosized ferrites.

\section{Acknowledgements}

The work has been performed within the framework of projects MAT2017-83631C3-2-R (Spanish "Ministerio de Economía, Industría y Competitividad”) and DRUGMAG, Nueva generación de plataformas teragnósticas contra el cáncer asistidas por partículas superparamagnéticas (Gobierno de Navarra, Departamento de Desarrollo Económico). The microscopy works have been conducted in the "Laboratorio de Microscopias Avanzadas" at "Instituto de Nanociencia de Aragon - Universidad de Zaragoza". Authors acknowledge the LMA-INA for offering access to their instruments and expertise. ILL and SpINS are acknowledged for beam time allocation (Proposal CRG-D1B-15-301 / CRG-2222). J. López-García acknowledges ILL for his Ph.D. contract. E. C. Mendonça, J. G. S. Duque thank to Brazilian agencies FAPITEC (PRONEX) and CNPq (455608/2014-8).

\section{References}

1.- D. S. Mathew, R.-S. Juang, An overview of the structure and magnetism of spinel ferrite nanoparticles and their synthesis in microemulsions, Chem. Eng. J. 129 (2007) 51-65. 
2.- B. Cruz-Franco, T. Gaudisson, S. Ammar, A. M. Bolarín-Miró, F. Sánchez de Jesús, F. Mazaleyrat, S. Nowak, G. Vázquez-Victorio, R. Ortega-Zempoalteca, R. Valenzuela, Magnetic Properties of Nanostructured Spinel Ferrites, IEEE Trans. Mag. 50 (2014) 2800106-2800106.

3.-T. Tatarchuk, M. Bououdina, J. J. Vijaya, L. J. Kennedy, Spinel Ferrite Nanoparticles: Synthesis, Crystal Structure, Properties, and Perspective Applications, In: Fesenko O., Yatsenko L. (eds) Nanophysics, Nanomaterials, Interface Studies, and Applications. NANO 2016. Springer Proceedings in Physics, vol 195. Springer (2017) doi.org/10.1007/978-3-319-56422-7_22.

4.- N. Sanpo, C. C. Berndt, C. Wen, J. Wang, New Approaches to the Study of Spinel Ferrite Nanoparticles for Biomedical Applications, M. Aliofkhazraei, A.S.H. Makhlouf (eds.), Handbook of Nanoelectrochemistry, Springer International Publishing Switzerland 2016

DOI 10.1007/978-3-319-15266-0_12, 1417-1441.

5.- H. Su, X. Tang, H. Zhang, Y. Jing, F. Bai, Low-loss magneto-dielectric materials: Approaches and developments, J. Electron. Mater. 43 (2014) 299-307.

6.- K. K. Kefeni, B. B. Mamba, T.A.M. Msagati, Application of spinel ferrite nanoparticles in water and wastewater treatment: A review, Sep. Purif. Technol. 188 (2017) 399-422.

7.- G.V. Duong, R.Sato Turtelli, W.C. Nunes, E. Schafler, N. Hanh, R. Grössinger, M. Knobel, Ultrafine $\mathrm{Co}_{1-x} \mathrm{Zn}_{x} \mathrm{Fe}_{2} \mathrm{O}_{4}$ particles synthesized by hydrolysis: effect of thermal treatment and its relationship with magnetic properties, J. Non-Cryst. Solids 353 (2007) 805-807.

8.- R. Arulmurugan, B. Jeyadevan, G. Vaidyanathan, S. Sendhilnathan, Effect of zinc substitution on Co-Zn and Mn-Zn ferrite nanoparticles prepared by co-precipitation, J. Magn. Magn. Mat. 288 (2005) 470-477.

9.- G.A. Petit, D.W. Forester, Mössbauer study of Co-Zn ferrites, Phys. Rev. B 4 (1971) 3912-3923.

10.- B. Antic, M. Perovic, A. Kremenovic, J. Blanusa, V. Spasojevic, P. Vulic, L. Bessais and E. S. Bozin, An integrated study of thermal treatment effects on the microstructure and magnetic properties of Zn-ferrite nanoparticles, J. Phys.: Condens. Matter 25 (2013) 086001 .

11.- S.R. Liu, D.H. Ji, J. xu, Z.Z. Li, G.D. Tang, R.R. Bian, W.H. Bian, W.H. Qi, Z.F. Shang, X.Y. Zhang, Estimation of cation distribution in spinel ferrites $\mathrm{Co}_{1+x} \mathrm{Fe}_{2-x} \mathrm{O}_{4}(0.0$ $\leq x \leq 2.0)$ using the magnetic moments measured at $10 \mathrm{~K}$, , J. Alloys Compd. 581 (2013) 6161-624.

12.- M. Veverka, Z. Jirak, O. Kaman, K. Knizek, M. Marysko, E. Pollert, K. Zavta, A. Lancok, M. Dlouha, S. Vratislav, Distribution of cations in nanosize and bulk Co-Zn ferrites, Nanotechnology 22 (2011) 345701. 
13.- R. Viñas, I. Alvárez-Serrano, M.L. López, C. Pico, M.L. Veiga, F. Mompeán, M. García-Hernández, Influence of particle sizes on the electronic behavior of Zn xCol$x \mathrm{Fe}_{2} \mathrm{O}_{4}$ spinels $(x=0.2,0.3)$, J. Alloys Compd.601 (2014) 130-139.

14.- C.B.R. Jesus, E.C. Mendonça, L.S.Silva, W.S.D.Folly, C.T.Meneses, J.G.S.Duque, Weak ferromagnetic component on the bulk $\mathrm{ZnFe}_{2} \mathrm{O}_{4}$ compound, J.Magn.Magn. Mat. 350 (2014) $47-49$.

15.- S.D. Bhame, P.A. Joy, Enhanced sensitivity in magnetostrictive spinel ferrite Col${ }_{x} \mathrm{Zn}_{x} \mathrm{Fe}_{2} \mathrm{O}_{4}$, J. Magn. Magn. Mat. 447 (2018) 150-154.

16.- M. Veverka, P.Veverka, Z.Jirak , O.Kaman , K.Knızek, M.Marysko, E.Pollert, $\mathrm{K}$.Zaveta, Synthesis and magnetic properties of $\mathrm{Co}_{1-x} \mathrm{Zn}_{x} \mathrm{Fe}_{2} \mathrm{O}_{4}$,nanoparticles as materials for magnetic fluid hyperthermia J . Magn. Mag. Mat. 322 (2010) 2386-2389

17.- T.J. Shinde, A.B. Gadkari, P.N. Vasambekar, Magnetic properties and cation distribution of nanocrystalline Ni-Zn ferrites, J. Magn. Magn. Mat. 333 (2013) 152-155.

18.- R.Arulmurugan, G. Vaidyanathan, S. Sendhilnathan, B. Jeyadevan, Thermomagnetic properties of $\mathrm{Co}_{1-x} \mathrm{Zn}_{x} \mathrm{Fe}_{2} \mathrm{O}_{4}(x=0.1-0.5)$ nanoparticles, J. Magn. Magn. Mat. 303 (2006) 131-137.

19.- P. Kaur, M. L. Aliru, A. S. Chadha, A. Asea, S. Krishnan, Hyperthermia using nanoparticles - Promises and pitfall, Int. J. Hyperthermia, 32 (2016) 76-88.

20.- N. Lee, D. Yoo, D. Ling, M. H. Cho, T. Hyeon, J. Cheon, Iron oxide based nanoparticles for multimodal imaging and magnetoresponsive Therapy, Chem. Rev., 115 (2015), 10637-10689.

21.- W. Aadinath, T. Ghosh, C. Anandharamakrishnan, Multimodal magnetic nanocarriers for cancer treatment: challenges and advancements, J. Magn. Magn. Mat., 401 (2016) 1159-1172.

22.- M. Veverka, K. Zaveta, O. Kaman, P. Veverka, K. Knizek, E. Pollert, M. Burian, P. Kaspar, Magnetic heating by silica-coated Co-Zn ferrite particles, J. Phys. D: appl. Phys 47 (2014) 065503.

23.- C. T. Meneses, J. G. S. Duque, L. G. Vivas, M. Knobel, Synthesis and characterization of TM-doped $\mathrm{CuO}(T M=F e, N i)$, J. Non. Cryst. Solids 354 (2008) 4830.

24.- J. Rodríguez-Carvajal, Recent advances in magnetic structure determination by neutron powder diffraction, Physica B 192 (1993) 55.

25.- L.B. Kiss, J. Söderlund, G.A. Niklasson, C.G. Granqvist, The real origin of lognormal nanoparticles in vapor growth processes, NanoStructured Materials 12 (1999) 327-332.

26.- F. Gözäk, Y. Köseoglu, A. Byakal, H. Kavas, Synthesis and characterization of $\mathrm{Co}_{x} \mathrm{Zn}_{1-x} \mathrm{Fe}_{2} \mathrm{O}_{4}$ magnetic nanoparticles via a PEG-assisted route, J. Magn. Magn. Mat. 321 (2009) 2170-2177. 
27.-V. Mameli, A. Musinu, A. Ardu, G. Ennas, D. Peddis, D. N iznansky, C. Sangregrorio, C. Innocenti, N.T.K Thanh, C. Cannas, Studying the effect of Znsubstitution on the magnetic and hyperthermic properties of cobalt ferrite nanoparticles, Nanoscale 8 (2016) 10124-10137.

28.- A.M. Wahda, M.B. Mohamed, N.G. Imam, Correlating structural, magnetic and liminiscence properties with the cation distribution $\mathrm{Co}_{0.5} \mathrm{Zn}{ }_{0.5+x} \mathrm{Fe}_{2-x} \mathrm{O}_{4}$ nanoferrite, J. Magn. Magn. Mat. 408 (2016) 51-59.

29.- G. Muscas, N. Yaacoub, G. Concas, F. Sayed, R. Sayed Hassan, J. M. Greneche, C. Cannas, A. Musinu, V. Foglietti, S. Casciardi, C. Sangregorio, D. Peddis, Evolution of the magnetic structure with chemical composition in spinel iron oxide nanoparticles, Nanoscale 7 (2015) 13576.

30.- W. C.K. Poon, E.R. Weeks, C.P. Royall, On measuring colloidal volume fractions, Soft Matter 8 (2012) 21-30.

31.- Kanna M. Krishnan, Fundamentals and applications of magnetic materials, Oxford University Press 2016, p. 372.

32.- D. Peddis, M.V. Mansilla, S. Morup, C. Canna, A. Musinu, G. Piccaluga, F.D'Orazio, F. Lucari, D. Fiorani, Spin-canting and magnetic anisotropy in ultrasmall $\mathrm{CoFe}_{2} \mathrm{O}_{4}$ nanoparticles, J. Phys. Chem. B 112 (2008) 8507-8513.

33.- K. Nadeem, H. Krenn, T. Traussnig, R. Würschum, D.V. Szabo, I. Letofsky-Papst, Effect of dipolar and excahnge interactions on magnetic blocking of maghemite nanoparticles, J. Magn. Magn.Mat. 323 82011) 1998-2004

34.- R.M. Bothorth, E.F. Tilden, A.J. Williams, Anisotropy and magnetization of some ferrites, Phys. Rev. B 99 (1955) 1788-1798.

35.- H. Parmar, P. Acharya, R.V.Upadhyay, V.Siruguri, S. Rayaprol, Low temperature magnetic ground state in bulk $\mathrm{Co}_{0.3} \mathrm{Zn}_{0.7} \mathrm{Fe}_{2} \mathrm{O}_{4}$ spinel ferrite system: Neutron diffraction, magnetization and ac-susceptibility studies, Solid State Commun.153 (2013) 60-65.

36.- B.D. Cullity, C.D. Graham, Introduction to Magnetic Materials, Wiley 2001.

37.- S. Chikazumi, Physics of Magnetism, Wiley 1964, p. 274.

38.- I.C. Niebedim, M. Vinitha, P.J. Praveen, D. Das, D.C. Jiles, Temperature dependence of the structural, magnetic and magnetostrictive properties of zinc-substituted cobalt ferrite, J. Appl. Phys. 113 (2013) 192904.

39.- A. Franco, F.C. Silva, High temperature magnetic properties of cobalt ferrite nanoparticles, Appl. Phys. Lett. 96 (2010) 172505.

40.- J. Sánchez-Marcos, E. Mazario, J. A. Rodriguez-Velamazan, E. Salas, P. Herrasti, N. Menendez, J. Alloys Compd. 739 (2018) 909-917. 
41- C. Vázquez-Vázquez, M.A. Lopez-Quintela, M.C. Buján-Nuñez, J. Rivas, Finite size and Surface effects on the magnetic properties of cobalt ferrite nanoparticles, J. Nanopart. Res 13 (2011) 1663-1676.

42.- G.F. Goya, T.S. Berquó, F.C. Fonseca, M.P. Morales MP Static and dynamic magnetic properties of spherical magnetite nanoparticles, J. Appl. Phys. 94 (2003) 35203528 .

43.- H. Sozeri , Z. Durmus, A. Baykal, Structural and magnetic properties of triethylene glycol stabilized $\mathrm{Zn}_{x} \mathrm{Co}_{1-x} \mathrm{Fe} 2 \mathrm{O} 4$ nanoparticles, Mater. Res. Bull. 47, 2442 (2012)

44.- R. Topkaya, A. Baykal, A. Demir, Yafet-Kittel-type magnetic order in Znsubstituted cobalt ferrite nanoparticles with uniaxial anisotropy J. Nanopat. Res. 15 (2013) 1359.

45.- S.N. Dipali, V.J. Swati, M. K. Vishwajeet R. A. Bohara, K.H. Chang, S.M. Sawanta, S. H. Pawar, Cation distribution, structural, morphological and magnetic properties of Co $_{1-x} Z n x F e 2 O 4(x=0-1)$ nanoparticles, RSC Adv. 5 (2015) 2538.

46.- L. Vegard, Die konstitution der mischkristalle und die raumfüllung der atome, Zeitschrift für Physik 5 (1921) 17-26.

47.- Crystallography Open Database, www.crystallography.net.

48.-A.V.Raut, R.S.Barkule, D.R.Shengule, K.M.Jadhav, Synthesis, structural investigation and magnetic properties of $\mathrm{Zn}^{2+}$ substituted cobalt ferrite nanoparticles prepared by the sol-gel auto-combustion technique, J. Magn. Mag. Mat. 358-359 (2014) $87-92$

49.- G. Barrera, M. Coisson, F. Celagato, S. Raghuvanshi, F. Mazaleyrat, S.N. Kane, P. Tiberto, Cation distribution effect on static and dynamic magnetic properties of Col${ }_{x} \mathrm{Zn}_{x} \mathrm{Fe}_{2} \mathrm{O}_{4}$ ferrite powders, J. Magn. Mag. Mat. 456 (2018) 372-380.

50.- L. Néel, Aimantation à saturation des ferrites mixtes de nickel et de zinc, C. R. Acad. Sci. Paris 230 (1950) 375.

51.- F. Lloret, M. Julve, J. Cano, R. Ruiz-García , Emilio Pardo, Magnetic properties of six-coordinated high-spin cobalt(II) complexes: Theoretical background and its application, Inorg. Chim. Acta 361 (2008) 3432.

52.- R. L. Carling, Magnetochemistry, Springer-Verlag,1986

53.- Y. Yafet, C. Kittel, Antiferromagnetic Arrangements in Ferrites, Phys. Rev. 87 (1952) 290.

54.- D. Peddis, M. V. Mansilla, S. Mørup, C. Cannas, A. Musinu, G. Piccaluga, F. D'Orazio, F. Lucari, D. Fiorani, Spin-Canting and Magnetic Anisotropy in Ultrasmall $\mathrm{CoFe}_{2} \mathrm{O}_{4}$ Nanoparticles, J. Phys. Chem. B 112 (2008) 8507. 
55.- S. R. Naik, A. V. Salker, S. M. Yusuf, S.S. Meena, Influence of $\mathrm{Co}^{2+}$ distribution and spin-orbit coupling on the resultant magnetic properties of spinel cobalt ferrite nanocrystals, J. of Alloys and Comp. 566 (2013) 54.

56.- I. Andreu, E. Natividad, Accuracy of available methods for quantifying the heat power generation of nanoparticles for magnetic hyphertermia, Int. J. Hyperthermia 29 (2013) 739-751.

57.- E. Garaio, O. Sandre, J. M. Collantes, J. A. Garcia, S. Mornet, F. Plazaola, Specific absorption rate dependence on temperature in magnetic field hyperthermia measured by dynamic hysteresis losses (ac magnetometry), Nanotechnology 26 (2015) 015704.

58.-Ö. Celik, T. Firat, Synthesis of FeCo magnetic nanoalloys and investigation of heating properties for magnetic fluid hyperthermia, J. Magn. Mag. Mat. 456 (2018) 1116.

59.- A.T, Nelson, J.T. white, d.A. Anderson, J.A. Aguiar, K.J. McClellan, D.D. Byler, M.P. short, C.R. Stanek, Thermal expansion, heat capacity and thermal conductivity of nickel ferrite ( $\mathrm{NiFe}_{2} \mathrm{O}_{4}$ ), J. Am. Ceram. Soc. 95 (2014) 1559-1565. 